\title{
ESQUEMA DE LOS PRINCIPIOS DEL DERECHO ADMINISTRATIVO SANCIONADOR
}

\author{
Alejandro Vergara Blanco ${ }^{1}$
}

SUMARIO: I. Naturaleza y principios del Derecho Administrativo Sancionatorio. 1. Naturaleza de las sanciones administrativas. 2. Recepción de principios del derecho administrativo sancionatorio en la Constitución y en la jurisprudencia del Tribunal Constitucional. II. Principios inspiradores del ius puniendi, en su manifestación administrativa. II. Principios inspiradores del ius puniendi, en su manifestación administrativa. 1. Principio de legalidad. 2. Principio de tipicidad. 3. Principio de la culpabilidad. 3. Principio de la culpabilidad. 4. Principio non bis in idem. 5. Principio de la proporcionalidad. 6. Derecho a la presunción de inocencia. III. El procedimiento sancionatorio: procedimiento legal. Conclusiones. Bibliografía.

RESUMEN: Trátase en este trabajo de una exposición sistematizada de los principios que se aplican en materia sancionatoria a nivel administrativo. Se describe en él su naturaleza jurídica, los principios que la inspiran, sus manifestaciones, y cuál es la expresión normativa del procedimiento sancionatorio de la especie.

Palabras clave: Administración - Potestad sancionatoria - Naturaleza jurídica - Principios - Procedimiento.

Ofrezco, a efectos de sistematización, este sencillo esquema de los principios que cabe aplicar en materia de sanciones administrativas ${ }^{2}$.

La potestad sancionatoria de la administración cabe distinguirla de la potestad sancionatoria penal, aunque ambas son reflejo del ius puniendi del Estado; esta surge de la potestad jurisdiccional del Estado (solo los Tribunales imponen propiamente sanciones penales, materia estudiada por el "derecho penal") y aquella surge de la potestad de administrar (la Administración puede imponer directamente sanciones, las que legalmente no se reputan "penas", en virtud del artículo 20 del Código Penal, pero cuyo ejercicio que puede ser revisado por los Tribunales).

\footnotetext{
1 Doctor en Derecho, Universidad de Navarra. Profesor de Derecho Administrativo Económico, Pontificia Universidad Católica de Chile.

2 Esquema que se sigue, igualmente, en nuestro libro: Derecho Eléctrico, Santiago, Editorial Jurídica de Chile, 2004, pp. 317-327. de ahí que los ejemplos que utilizo en este escrito son de la normativa eléctrica, pero aplicables a toda potestad sancionatoria.
} 
En muchos textos legales vigentes se le otorga a la Administración la potestad sancionatoria (como es el caso, por ejemplo, de los artículos 15 y siguientes, Ley $\mathrm{N}^{\circ} 18.410$ de 1985 , que crea la Superintendencia de Electricidad y Combustibles, en materia eléctrica), potestad cuya legitimidad rara vez se discute ${ }^{3}$, pues en definitiva su ejercicio siempre queda vinculado a la juridicidad y al posterior control jurisdiccional, siendo esto último algo ineludible en todo acto de la Administración.

\section{Naturaleza y PRINCIPIOS Del Derecho AdMinistrativo SANCIONATORIO}

Antes de todo análisis dogmático de toda norma que establezca potestades sancionadoras de la Administración, es necesario revisar la naturaleza y los principios que regulan el ejercicio de esta potestad, para verificar:

(i) por un lado, desde la perspectiva de la Administración, sus límites y posibilidades de acción, y

(ii) por otro, los derechos que al respecto le asegura el orden jurídico al administrado.

\section{Naturaleza de las sanciones administrativas}

Dada la usual diferencia cuantitativa de las penas que son susceptibles de imponer en el derecho penal, por un lado, en que son más graves, por afectar la libertad personal; y, por otro, en el derecho administrativo sancionatorio, en que son menos graves, pues en general se reducen a las multas y a otras sanciones patrimoniales, se podría estimar que la naturaleza misma de las sanciones administrativas, es distinta que la naturaleza de las sanciones penales, para, a partir de tal diferencia, postular la inaplicabilidad de los tradicionales principios del ius puniendi: como la juridicidad, tipicidad, culpabilidad o non bis in idem.

La distinción material entre penas administrativas y penales ha sido esgrimida mediante una interpretación algo forzada de lo dispuesto en el artículo 20 del Código Penal ${ }^{4}$, en cuanto señala que "no se reputan penas (...), las multas (...) que los superiores impongan a (..) administrados en uso de su[s] (...) atribuciones gubernativas". No obstante, del tenor

No obstante, ver: Soto Kioss, Notas, cit., y Aróstica, Algunos, cit., aceptan con reservas esta potestad de la Administración.

Así: NOvOA, Eduardo: Curso de derecho penal chileno, Santiago, Editorial Jurídica de Chile, 1960, I, pp. 40-41. 
de esta disposición no puede desprenderse esa diferente naturaleza ${ }^{5}$; antes al contrario, tal disposición legal (al señalar que no se "reputan": no niega que "son" penas), junto con el artículo 501 del Código Penal, realiza un mandato de regímenes procesales aplicables, y de entidades estatales con potestad para hacerlo: las penas del Código Penal corresponde aplicarlas a los Tribunales, directamente; las penas administrativas corresponde aplicarlas a los órganos administrativos, sin perjuicio de la revisión jurisdiccional ulterior, en este último caso.

Hoy en general, no se discute que en ambos casos existen sanciones que afectan a las personas y que, materialmente, son de idéntica naturaleza.

De lo señalado se desprende la unidad material de la naturaleza del ius puniendi estatal, o al menos de su esencial similitud, de lo que surge, a su vez, la necesidad de respetar en el ejercicio de ambas clases de sanciones (penales y administrativas) los principios que al efecto ha acogido la Constitución y que se entienden parte integrante en el actual ordenamiento jurídico.

2. Recepción de principios del Derecho Administrativo Sancionatorio en la Constitución y en la jurisprudencia del Tribunal Constitucional

En esta materia son esenciales los incisos $6^{\circ}, 7^{\circ}$ y $8^{\circ}$ del artículo 19 $\mathrm{N}^{\circ} 3$ de la Constitución, relativo a "flta igual protección de la ley en el ejercicio de sus derechos", según los cuales:

"La ley no podrá presumir de derecho la responsabilidad penal.

Ningún delito se castigará con otra pena que la que señale una ley promulgada con anterioridad a su perpetración, a menos que una nueva ley favorezca al afectado.

Ninguna ley podrá establecer penas sin que la conducta que se sanciona esté expresamente descrita en ella".

Al respecto, por su texto tan expresivo, solo nos basta con transcribir lo que ha señalado la Sentencia de Tribunal Constitucional, Rol N ${ }^{\circ} 244$, 26/8/1996 (a propósito de la Ley de Caza), en sus considerandos $9^{\circ}, 10^{\circ}$, $11^{\circ}$ y $12^{\circ}$ :

"9". Que, los principios inspiradores del orden penal contemplados en la Constitución Política de la República han de aplicarse, por regla general, al derecho administrativo sancionador, puesto que ambos son manifestaciones del ius puniendi propio del Estado;

5 Cfr.: Cury, op. cit., p. 77; Aróstica, op. cit., pp. 73-75; AlCAlde, op. cit., p. 226 ss. 
10. Que, entre ellos, es necesario destacar los principios de legalidad y de tipicidad, los cuales no se identifican, sino que el segundo tiene un contenido propio como modo de realización del primero. La legalidad se cumple con la previsión de los delitos e infracciones y de las sanciones en la ley, pero la tipicidad requiere de algo más, que es la precisa definición de la conducta que la ley considera reprochable, garantizándose así el principio constitucional de seguridad jurídica y baciendo realidad, junto a la exigencia de una ley previa, la de una ley cierta;

$11^{\circ}$. Que, en este sentido, ambos principios se encuentran consagrados en los incisos séptimo y octavo del $N^{o} 3^{\circ}$ del artículo 19, de la Carta Fundamental, de acuerdo con los cuales "Ningún delito se castigará con otra pena que la que señale una ley promulgada con anterioridad a su perpetración, a menos que una nueva ley favorezca al afectado", y "Ninguna ley podrá establecer penas sin que la conducta que se sanciona esté expresamente descrita en ella".

$12^{\circ}$. Que, de esta forma, la Constitución precisa de manera clara que corresponde a la ley y solo a ella establecer al menos el núcleo esencial de las conductas que se sancionan, materia que es así, de exclusiva y excluyente reserva legal, en términos tales, que no procede a su respecto ni siquiera la delegación de facultades legislativas al Presidente de la República, en conformidad con lo que dispone el artículo 61, inciso segundo, de la Constitución Política"6.

De lo anterior podemos desprender claramente que el ius puniendi del Estado, ya sea en su manifestación penal o administrativa, dada la evidente naturaleza común, en su ejercicio debe respetar los mismos principios de legalidad y tipicidad, y sus derivados, que ya veremos (culpabilidad y non bis in idem). En otras palabras, aunque exista una dualidad de sistemas represivos del Estado, en ambos casos, por su unidad material, aunque el procedimiento sea distinto, se han de respetar estos principios de fondo: es el mismo ius puniendi del Estado. Entonces, los principios conocidos generalmente como del derecho penal, hay que considerarlos como principios generales del derecho sancionador, y el Tribunal Constitucional ha señalado claramente que tales principios tradicionales del derecho penal se aplican a la esfera sancionatoria administrativa $^{7}$.

El énfasis es agregado.

Si bien con algunos "matices", como señala la doctrina (vid. GARCf́A DE ENTERRla y FERNÁNDEZ, op. cit., II, p. 170), y que desarrollaremos más adelante. 


\section{PRINCIPIOS INSPIRADORES DEL IUS PUNIENDI, EN SU MANIFESTA- CIÓN ADMINISTRATIVA.}

Corresponde ahora desarrollar tales principios del derecho sancionador en vía administrativa; esto es, cuando la Administración ejerce su potestad administrativa de sanción.

Si bien la sentencia del Tribunal Constitucional citada solo desarrolla los principios de la legalidad y de la tipicidad, en cuanto al ius puniendi, desarrollaremos también sus derivados, ya enunciados, los cuales no solo tienen un tradicional acogimiento doctrinario y jurisprudencial ${ }^{8}$, sino que se encuentran consagrados en nuestro ordenamiento jurídico.

En algunos casos, por ejemplo en materia eléctrica, la Administración, siguiendo un texto legal algo escueto (artículo 15, Ley 18.410/ 1985, citada), y en una parte inconstitucional (algo lamentablemente usual: aceptar la tipicidad por vía reglamentaria), no ha respetado siempre estos principios en su práctica sancionatoria, y la jurisprudencia se ha mostrado renuente a su análisis.

\section{Principio de legalidad}

Su formulación más tradicional es el principio nullum crimen, nulla poena sine lege. En la recepción constitucional chilena, ha de existir una ley promulgada con anterioridad, la que deberá determinar la pena que corresponde (artículo19 $\mathrm{N}^{\circ} 3$ inciso $7^{\circ}$ de la Constitución).

Esto supone, de inmediato, como lo ha señalado la sentencia del Tribunal Constitucional citada:

$1^{\circ}$ Solo la ley puede establecer delitos y sus penas. En palabras del Tribunal Constitucional: "corresponde a la ley y solo a ella establecer al menos el núcleo esencial de las conductas que se sancionan, materia que es así, de exclusiva y excluyente reserva legal" (considerando $12^{\circ}$ ).

$2^{\circ}$ La proscripción del reglamento en la materia. Esto es, el reglamento en ningún caso puede establecer delitos, ni de ahí derivarse penas. Para el caso de la potestad sancionatoria de la Administración, implica que esta solo puede ser ejercida cuando haya sido atribuida por una norma de rango legal. Esto, por lo demás, es el reflejo del principio general de la juridicidad de la Administración, desarrollado más arriba.

8 AlCALDE, cir,, p. 229, aporta varios fallos (sin señalar sede de publicación) en que se deja de manifiesto la identidad de naturaleza jurídica de las sanciones penales y administrativas, y aplican los mismos principios en ambos casos. 
La llamada "colaboración reglamentaria" está no solo limitada sino virtualmente proscrita en materia de ius puniendi estatal, ya sea penal o sancionatorio administrativo, y no cabe, en ningún caso, considerar al reglamento como origen de algún ilícito administrativo o de alguna pena.

Entonces, de acuerdo a este principio las sanciones solo son legítimas en la medida que hayan sido establecidas en leyes y no en reglamentos, por lo que cabe señalar, que carece de legitimidad constitucional, por ejemplo, el artículo 15 inciso $1^{\circ}$ de la Ley $\mathrm{N}^{\circ} 18.410 / 1985$, citada, al prescribir que las "infracciones de (...) reglamentos (...) podrán ser objeto de la aplicación por [la Superintendencia] de las sanciones...". No es concordante con el principio de la legalidad considerar que la infracción de un reglamento puede dar origen a una conducta sancionable, pues ello quebranta el principio de la legalidad, y solo es posible establecer sanciones mediante "una ley promulgada con anterioridad a su perpetración" (artículo $19 \mathrm{~N}^{\circ} 3$ inciso $7^{\circ}$ de la Constitución).

$\mathrm{Y}$, a partir de este principio, ninguna resolución administrativa que imponga una sanción podría basarse en una infracción a un reglamento; esta sanción así impuesta resulta claramente inconstitucional, y un texto legal, en cuanto recoja al reglamento como fuente de una conducta sancionable administrativamente, es en sí mismo inconstitucional; pues: toda pena debe fundarse en ley.

\section{Principio de tipicidad}

Este principio es una derivación del principio general de la certeza (lex certa), y en su virtud, la ley respectiva (nunca el reglamento, según lo dicho: principio de legalidad) debe contener ella misma una descripción precisa de la conducta específica que podrá ser sancionada.

No caben, por lo tanto, fórmulas genéricas, abiertas o indeterminadas de infracción, llamadas también "leyes penales en blanco".

Lo que debe emanar del cumplimiento de este principio es el establecimiento, por la ley, de una descripción y determinación de la o las conductas que quedan sometidas a sanciones, de tal manera que sea posible predecir con alguna certeza la sanción que se impondrá en caso de que alguien incurra en la conducta así "tipificada".

En términos del Tribunal Constitucional, en su sentencia citada, lo que se requiere para que una ley sea considerada respetuosa del principio de la tipicidad es: "la precisa definición de la conducta que la ley considera reprochable".

En materia eléctrica, por ejemplo, cabrá revisar si el tipo que se establece en el artículo 15 inciso $1^{\circ}$ de la Ley $N^{\circ} 18.410 / 1985$ cumple medianamente este principio, al referirse a "infracciones de las leyes...", de un modo tan genérico, que debe ser precisado y graduado en cuanto 
a sus sanciones, según la gravedad de sus resultados, establecidos en los incisos $3^{\circ}$ y $4^{\circ}$ de tal disposición legal.

\section{Principio de la culpabilidad}

La culpabilidad, como principio, es lo contrario a la presunción de culpa por el derecho, sin requerir dolo o culpa personal en la conducta sancionable; esto es, a la llamada "responsabilidad objetiva". En virtud de este principio queda erradicada de todo ordenamiento jurídico sano la aplicación de sanciones sin culpabilidad personal, esto es, sin dolo o culpa en la acción sancionable.

No cabe en ningún caso imponer una sanción, en este caso, administrativa, a quien no pueda dirigírsele un reproche personal por la ejecución de la conducta prohibida?

De este modo, según los términos del artículo15 de la Ley $\mathrm{N}^{\circ}$ 18.410/1985, solo cabe aplicar sanciones a las "empresas, entidades o personas naturales" (inciso $1^{\circ}$ ), en la medida que por "hechos, actos u omisiones" (incisos $3^{\circ} 4^{\circ}$ y $5^{\circ}$ ) de ellas mismas, se hubiese incurrido en las conductas señaladas en la ley, a las que cabrá aplicarles las sanciones establecidas también en la ley. De lo anterior, se deriva, que en aplicación de este principio de la culpabilidad, en general, y específicamente en materia eléctrica, está proscrita:

$1^{\circ}$ La llamada "responsabilidad objetiva", esto es, imponer una sanción sin verificar previamente la culpabilidad personal, a la luz simplemente de un hecho que aparente ser el resultado de una acción u omisión cuyo nexo culposo no se haya establecido.

$2^{\circ} \quad$ La "responsabilidad solidaria", aun cuando se encubra larvadamente en otras figuras, no es admisible, pues se quebranta el necesario nexo culposo personal en la aplicación de la sanción.

Estos dos casos de responsabilidad "objetiva" y (larvadamente) "solidaria" veremos que ha tenido algún acogimiento práctico en materia eléctrica, en resoluciones de la SEC y un descuido jurisprudencial, que será analizado más adelante.

\section{Principio non bis in idem}

Este principio debe ser considerado íntimamente vinculado a los principios de la legalidad y de la tipicidad, pues se deriva de estos; por lo que este principio non bis in idem, tendría ese mismo estatuto de

9 Cfr.: CURY, op. cit., p. 80. 
principio general, ya que lo que está llamado a impedir es la doble punición. Y si en virtud de los principios de legalidad y tipicidad se impide aplicar alguna sanción sin previa ley existente y descriptora de la conducta; en virtud de este principio non bis in idem se impide aplicar una nueva sanción por una conducta ya sancionada.

Desde la perspectiva administrativa, tiene dos vertientes este principio. Por una parte, impide que un mismo hecho sea considerado a la vez delito penal y delito administrativo; $y$, por otra, que un mismo hecho personal sea considerado a la vez objeto de dos sanciones de tipo administrativo; por ejemplo, que de un mismo hecho se deriven dos o más multas.

\section{Principio de la proporcionalidad}

Supone este principio una correspondencia entre la infracción y la sanción impuesta, con el fin de impedir que la ley autorice y que la autoridad tome medidas innecesarias y excesivas. Este principio impone criterios de graduación de las sanciones, basados en diversos criterios, incluso derivados de otros principios, como la intencionalidad, la reiteración, los perjuicios causados, la reincidencia en la misma sanción, pero en períodos de tiempo acotados. Este principio, en nuestro sistema constitucional surge del artículo $19 \mathrm{~N}^{\circ} 3$ inciso $7^{\circ}$ in fine de la Constitución, dado que todo lo que "favorezca al afectado" debe ser considerado, y una ley aplicada sin la racional proporcionalidad puede ocasionar una "desproporción" en su aplicación, lo que impide este principio.

Este principio de la proporcionalidad está claramente acogido en los artículos 15,16 y $16 \mathrm{~A}$ de la Ley $\mathrm{N}^{\circ} 18.410 / 1985$. En todo caso, deben aplicarse en función de la culpabilidad "personal", pues de otro modo se produce una imposibilidad de aplicación de este principio. En otras palabras, si se infringe el principio de la culpabilidad (y se imponen, por ejemplo, sanciones de modo objetivo o larvadamente solidario, como se intenta en el caso que se analiza en este trabajo), ya se hace muy difícil aplicar este principio de la proporcionalidad.

\section{Derecho a la presunción de inocencia}

Este principio está consagrado en el artículo $19 \mathrm{~N}^{\circ} 3$ inciso $6^{\circ}$ de la Constitución, en una formulación in extremis: prohibiendo la presunción de derecho de la responsabilidad penal, y tiene como base el sistema de protección general de la libertad. Esta presunción de inocencia, que tiene rango constitucional no solo para la responsabilidad penal, sino para todo tipo de responsabilidad, y en especial para la responsabilidad sancionatoria administrativa, supone que solo sobre la base de 
pruebas efectivas, y cuyo aporte es carga de quien acusa, podrá alguien ser acusado y sancionado.

Este principio de la presunción de la inocencia quiere decir, entonces, que en un procedimiento sancionatorio administrativo, como el procedimiento que la SEC ha llevado adelante en esta causa, es la propia Administración (la SEC), en la fase de instrucción del procedimiento sancionatorio, la que debe aportar las pruebas que implican responsabilidad de quienes soporten una sanción.

\section{EL PROCEDIMIENTO SANCIONATORIO: PROCEDIMIENTO LEGAL}

La Administración, para llegar a aplicar una sanción debe seguir un procedimiento formal, a través del cual, con pleno respeto de la legalidad y de los principios de rango constitucional ya señalados, justifique a través de la prueba de los hechos pertinentes, y fundamente en el Derecho vigente las eventuales sanciones que imponga,

Hoy en Chile, a partir del 29 de mayo de 2003, ningún acto de la Administración debe dictarse sin el cumplimiento de lo señalado en la Ley $\mathrm{N}^{\circ} 19.880$, de esa fecha, la que "[e]stablece bases de los procedimientos administrativos que rigen los actos de los órganos de la Administración del Estado" (LBPA). Esta ley rige plenamente en los casos en que no hay procedimiento especial alguno; en caso contrario, el procedimiento especial preexistente se completa de modo "supletorio" con esta nueva ley. En esta ley se establecen una serie de principios relativos al procedimiento administrativo que deben ser respetados en la emisión de los actos sancionatorios de la Administración, so pena de posible invalidación (artículo 53 LBPA), u otros recursos administrativos y jurisdiccionales.

\section{CONCLUSIONES}

$1^{\circ}$ La potestad sancionatoria de la administración cabe distinguirla de la potestad sancionatoria penal, aunque ambas son reflejo del ius puniendi del Estado. Esta surge de la potestad jurisdiccional del Estado (solo los Tribunales imponen propiamente "penas" penales, materia estudiada por el "derecho penal") y aquella surge de la potestad de administrar (la Administración puede imponer directamente sanciones, las que legalmente no se reputan "penas", pero cuyo ejercicio que puede ser revisado por los Tribunales). De lo señalado se desprende la unidad material de la naturaleza del ius puniendi estatal, y la necesidad de respetar en su ejercicio los principios que al efecto ha acogido la CP y que se entienden parte integrante en el actual ordenamiento jurídico. 
$2^{\circ}$ El ius puniendi del Estado, ya sea en su manifestación penal o administrativa, dada la evidente naturaleza común, en su ejercicio debe respetar los mismos principios de legalidad y tipicidad, y sus derivados (culpabilidad y non bis in idem). En otras palabras, aunque exista una dualidad de sistemas represivos del Estado, en ambos casos, por su unidad material, aunque el procedimiento sea distinto, se han de respetar estos principios de fondo: es el mismo ius puniendi del Estado. Entonces, los principios conocidos generalmente como del derecho penal, hay que considerarlos como principios generales del derecho sancionador, y tales principios tradicionales del derecho penal se aplican a la esfera sancionatoria administrativa.

$3^{\circ}$ A partir del principio de la legalidad de las sanciones, ninguna resolución administrativa que imponga una sanción podría basarse en una infracción a un reglamento; una sanción así configurada y a partir de un reglamento impuesta resulta claramente inconstitucional, en cuanto recoge al reglamento como fuente de una conducta sancionable administrativamente, es en sí mismo inconstitucional; pues: toda pena debe fundarse en ley.

$4^{\circ}$ En cumplimiento del principio de tipicidad, el establecimiento, por la ley, de una descripción y determinación de la o las conductas que quedan sometidas a sanciones, debe hacerse de tal manera que sea posible predecir con alguna certeza la sanción que se impondrá en caso de que alguien incurra en la conducta así "tipificada".

$5^{\circ}$ En virtud del principio non bis in idem, queda prohibida la doble punición, a partir de un mismo hecho.

$6^{\circ}$ La Administración, para aplicar una sanción, debe tramitar previamente un procedimiento formal, a través del cual, con pleno respeto de la legalidad y de los principios de rango constitucional ya señalados, justifique a través de la prueba de los hechos pertinentes y fundamente en el Derecho vigente las eventuales sanciones que imponga.

\section{Algunas Referencias Bibliográficas}

1. En manuales de Derecho Administrativo:

Cassagne, Juan Carlos: Derecho Administrativo, Buenos Aires, LexisNexis, 2002, 1, pp. 435-460.

García de Enterría, Eduardo y Fernández, Tomás Ramón:

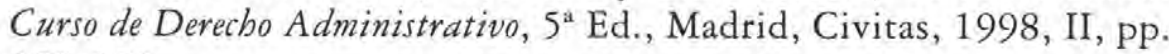
159-201.

2. Algunos textos monográficos:

SANZ GANDASEGUI, Francisco: La potestad sancionatoria de la administración: la Constitución española y el Tribunal Constitucional, Madrid, Edersa, 1985, 279 pp. 
SOTO Kloss, Eduardo: "Notas para el estudio de la potestad sancionatoria de la Administración", en: Boletín de Investigaciones, Facultad de Derecho, Pontificia Universidad Católica de Chíle, $N^{\text {os }} 44$ y 45 , 1979/1980, pp. 95-103.

Aróstica MALdonado, Iván: "Algunos problemas del derecho administrativo penal", en: Revista de Derecho, Universidad de Concepción, $\mathrm{N}^{\circ} 182,1987$, pp. 71-81.

BERMúdEZ SOTO, Jorge: "Elementos para definir las sanciones administrativas", en: Revista Chilena de Derecho (Número Especial), 1998, pp. 323-334.

3. Desde la perspectiva del Derecho Penal:

CURY URZÚA, Enrique: "Algunas reflexiones sobre la relación entre penas penales y administrativas", en: Boletín de Investigaciones, Facultad de Derecho, Pontificia Universidad Católica de Chile, Nos 44 y 45, 1979/1980, pp. 86-94; luego ampliado en su: Derecho penal. Parte General, $2^{\mathrm{a}}$ ed., Santiago, Editorial Jurídica de Chile, 1992, pp. 69-93.

4. Desde la perspectiva del Derecho Civil:

CORRal TAlCiani, Hernán: Lecciones de responsabilidad civil extracontractual, Santiago, Editorial Jurídica de Chile, 2003, pp. 18-19, que distingue breve y correctamente el tópico.

5. En fin, desde una perspectiva más general, véase lúcidos desarrollos sobre el tema en:

ALCALDE RODRÍGUEZ, Enrique: Los principios generales del derecho. Su función de garantía en el derecho público y privado chileno, Santiago, Ediciones Universidad Católica de Chile, 2003, pp. 224-239. 